\title{
The influence of varying dietary sodium content on circadian blood pressure profile in patients with salt-sensitive hypertension
}

\author{
Marta Sołtysiak, Krystyna Widecka, Tomasz Miazgowski, Anna Brzeska, Joanna Ziemak \\ Department of Hypertension and Internal Diseases, Pomeranian Medical University
}

\begin{abstract}
The pathogenesis of essential hypertension is not fully understood. Literature indicates the complexity of blood pressure regulating mechanisms with a high impact of genetics and environmental factors. Previous experimental studies have shown the importance of salt intake in the development of hypertension. The aim of the study was to explore the influence of varying dietary sodium content on circadian blood pressure profile in patients with salt-sensitive hypertension. The study was carried out among 69 salt-sensitive hypertensive patients ( 19 females i 50 males) mean aged $36.1 \pm 8.0$ years. Study protocol provided low sodium diet firstly then high sodium diet containing 10-20 mmol and 220-240 mmol of sodium per day respectively. On each of the diet ABPM was performed. Our results suggest that in salt-sensitive patients the reduction of salt intake may decrease blood pressure and restore its circadian profile and thus lead to the reduction in the rate of complications of hypertension.
\end{abstract}

key words: arterial hypertension, sodium sensitivity, blood pressure profile, sodium intake

Arterial Hypertens. 2016, vol. 20, no. 4, pages: 211-215

DOI: $10.5603 / A H .2016 .0024$

\section{Introduction}

The pathogenesis of essential hypertension is not fully understood. Literature indicates the complexity of blood pressure regulating mechanisms with a high impact of genetics and environmental factors. Previous experimental studies have shown the importance of salt intake in the development of hypertension. Since then blood pressure salt-sensivity is constantly studied. Depending on the blood pressure response to salt intake, patients are divided into salt-sensitive and salt-insensitive subjects. Salt-sensivity incidence among patients with hypertension is estimated at about $50 \%[1,2]$ while in healthy subjects at approximately $20 \%[3,4]$. It is widely known that blood pressure salt-sensivity prevalence is more frequent in black race and the elderly subjects than among caucasians and young people [5]. In addition, salt-sensitivity of blood pressure is common in obese patients with diabetes type 2 than those without the metabolic disorders [6, 7].

The mechanisms responsible for the blood pressure response to high-sodium diet are complex and only partly clarified. The salt-sensivity phenomenon is probably based on the interaction between kidney and neuroendocrine factors such as atrial natriuretic peptide (ANP), kinins, prostaglandins, but the further research are required for explanation. Salt-sensitivity of blood pressure is connectedwith a higher mortality due to cardiovascular events such as myocardial infarction and heart failure [8-12]. Large 24-hour variability of blood pressure values and nocturnal decline absence are considered as a good

Address for correspondence: Marta Soltysiak, MD

Department of Hypertension and Internal Diseases, Pomeranian Medical University ul. Unii Lubelskiej 1, 71-252 Szczecin, tel. (091) 425-35-50; fax: (091) 425-35-52 e-mail: marta.soltysiak00@gmail.com

V M Copyright (C) 2016 Via Medica, ISSN 2449-6170 
indicators of cardiovascular complications in patients with arterial hypertension [13]. In clinical practice ABPM (Ambulatory Blood Pressure Monitoring) is the best way to evaluate blood pressure profile.

The aim of the study was to explore the infuence of varying dietary sodium content on cicardian blood pressure profile in patients with salt-sensitive hypertension.

\section{Material and methods}

The study was carried out among 69 salt-sensitive hypertensive patients ( 19 females i 50 males) mean aged $36.1 \pm 8.0$ years; with mean BMI $23.5 \pm 0.9$ $\mathrm{kg} / \mathrm{m}^{2}$. In refferance to current guidelines, hypertension was diagnosed based on two different visits blood pressure measurments [16]. We excluded patients with prior diagnosis of secondary hypertension, heart failure, chronic kidney disease and those who were treated with hypertensive medications $[17,18]$. Salt-sensivity hypertension was diagnosed in refferance to the Sullivan [4] and Bigazzi [19] criteria, according to which hypertension can be considered as salt-sensitive when the mean arterial pressure (MAP) values rises above $10 \mathrm{~mm} \mathrm{Hg}$ with a change in the sodium intake from 10-20 $\mathrm{mmol} / 24 \mathrm{~h}$ (low sodium diet) to high: $220-240$ $\mathrm{mmol} / 24 \mathrm{~h}$ (high sodium diet).

Study protocol provided low sodium diet firstly then high sodium diet containing 10-20 $\mathrm{mmol}$ and 220-240 mmol of sodium per day respectively. The potassium content in all kinds of diet was constant at the level of $40-50 \mathrm{mmol} / 24 \mathrm{~h}$. Diet compliance was monitored by $24-\mathrm{h}$ sodium excretion level in the $24-\mathrm{h}$ urine collection. On each of the diet we performed 24-hour blood pressure monitoring (ABPM) (Spacelabs Healthcare) and analyzed 24-hour, daytime and nocturnal systolic, diastolic, and mean values. Non-dipping blood pressure profile was defined as reduction of $0-10 \%$ in overnight blood pressure [20]. PRA (plasma renin activity with normal range: 0.51-2.64 ng/ml/h), plasma aldosterone (normal range: $10-160 \mathrm{pg} / \mathrm{ml}$ ), serum sodium and potassium level, creatine were measured using commercially available assays.

The statistical evaluation was performed by using Wilcoxon test and, for comparison of skewedly distributed variables between the study groups, median values were calculated and Mann-Whitney $\mathrm{U}$ test was used. $\mathrm{P}$ values $<0.05$ were considered significant. All analyses were carried out in Statistica (Statsoft, Inc. USA).

\section{Results}

Table I shows the clinical and biochemical characteristics of patients with salt-sensitive hypertension.

Table II shows a comparison of mean $( \pm$ SD) blood pressure, measured of ABPM method, in sodium sensitive hypertensive patients on low-sodium and high-sodium diet.

Patients with salt-sensivity blood pressure had significantly higher mean blood pressure values of all the analyzed ABPM parameters while receiving high-sodium diet. Moreover, the nocturnal pressure decline was significantly lower during high-sodium dieting compared to the low-sodium diet.

Frequency of non-dippers and dippers in sodium sensitive hypertensive patients on low-and high-sodium diet shown in Table III.

Along with increases in the salt intake frequencies of non-dippers profile was also increased, what was confirmed by $\chi^{2}$ test $(\mathrm{p}<0,001)$.

Table IV shows mean value $( \pm S D)$ of creatinine clearance $(\mathrm{Ccr})$, urinary sodium $(\mathrm{UNa})$, potassium (UK), urinary volume (Uvol), concentrations of PRA and aldosterone in sodium sensitive hypertensive patients on low-and high-sodium diet. The 24-h sodium excretion increased according to salt intake. No significant differences in potassium excretion, and urine volume has been observed.

In addition, along with increases in the salt intake PRA inhibition and aldosterone levels decrease was observed.

Table I. Clinical and biochemical characteristics of salt-sensitive hypertensive patients

\begin{tabular}{|l|c|}
\hline & $\begin{array}{c}\text { Mean } \\
\mathbf{n}=69\end{array}$ \\
\hline Age (years) & $36.1 \pm 8.0$ \\
\hline BMI $\left[\mathrm{kg} / \mathrm{m}^{2}\right]$ & $23.5 \pm 0.9$ \\
\hline SBP $[\mathrm{mm} \mathrm{Hg}]$ & $157.2 \pm 9.1$ \\
\hline DBP $[\mathrm{mm} \mathrm{Hg}]$ & $101.4 \pm 3.1$ \\
\hline MAP[mm Hg] & $120.9 \pm 5.7$ \\
\hline Serum sodium $[\mathrm{mmol} / \mathrm{l}]$ & $142.8 \pm 2.3$ \\
\hline Serum potassium [mmol/l] & $4.3 \pm 0.2$ \\
\hline Uvol [ml/24h] & $1210 \pm 201$ \\
\hline UNa [ mmol/24h] & $109.4 \pm 5.0$ \\
\hline UK [mmol/24h] & $49.9 \pm 4.7$ \\
\hline Ccr [ml/min] & $106.1 \pm 8.0$ \\
\hline PRA [ng/Al/ml/h] & $2.50 \pm 0.51$ \\
\hline Aldosterone $[\mathrm{pg} / \mathrm{ml}]$ & $237.1 \pm 42.6$ \\
\hline
\end{tabular}

$\mathrm{BMI}$ — body mass index; SBP — systolic blood pressure; DBP — diastolic blood pressure; MAP — mean arterial pressure; Uvol — urine volume; $\mathrm{UNa}$ — sodium in 24h urine collection; UK — potassium in 24h urine collection; $\mathrm{Ccr}$ - creatinie clearance; PRA — plasma renin avtivity 
Table II. The comparison of mean ( \pm SD) blood pressure, estimated in ABPM method, in sodium sensitive hypertensive patients on lowsodium and high-sodium diet

\begin{tabular}{|l|c|c|c|}
\hline & Low sodium diet & High sodium diet & $p<$ \\
\hline 24 SBP $[\mathrm{mm} \mathrm{Hg}]$ & $130.5 \pm 5.8$ & $145.8 \pm 7.8$ & $\mathrm{p}<0.001$ \\
\hline $24 \mathrm{DBP}[\mathrm{mm} \mathrm{Hg}]$ & $92.5 \pm 7.9$ & $102.3 \pm 11.2$ & $\mathrm{p}<0.001$ \\
\hline $24 \mathrm{MAP}[\mathrm{mm} \mathrm{Hg}]$ & $109.4 \pm 5.5$ & $125.3 \pm 4.5$ & $\mathrm{p}<0.001$ \\
\hline SBPd [mm Hg] & $134.5 \pm 10.2$ & $152 \pm 6.2$ & $\mathrm{p}<0.001$ \\
\hline DBPd [mm Hg ] & $95.4 \pm 6.3$ & $106.2 \pm 6.2$ & $\mathrm{p}<0.001$ \\
\hline MAPd [mm Hg] & $115.4 \pm 5.0$ & $130.2 \pm 4.3$ & $\mathrm{p}<0.001$ \\
\hline SBPn $[\mathrm{mm} \mathrm{Hg}]$ & $110.1 \pm 7.8$ & $115.3 \pm 8.9$ & $\mathrm{p}<0.001$ \\
\hline DBPn $[\mathrm{mm} \mathrm{Hg}]$ & $69.1 \pm 5.4$ & $75.1 \pm 7.5$ & $\mathrm{p}<0.001$ \\
\hline MAPn [mm Hg] & $101.8 \pm 5.9$ & $119.3 \pm 5.9$ & $\mathrm{p}<0.001$ \\
\hline CV (\%) & $12.0 \pm 3.5$ & $8.8 \pm 3.2$ & $\mathrm{p}<0.001$ \\
\hline
\end{tabular}

24 SBP - 24-hour systolic blood pressure; $24 \mathrm{DBP}$ - 24-hour diastolic blood pressure; $24 \mathrm{MAP}$ - 24-hour mean arterial pressure; SBPd — daytime systolic blood pressure; DBPd — daytime diastolic blood pressure; $\mathrm{MAPd}$ - daytime mean arterial pressure; $\mathrm{SBPn}$ — nocturnal systolic blood pressure; $\mathrm{DBPn}$ - nocturnal diastolic blood pressure; MAPn — nocturnal mean arterial pressure; CV — coefficient of variation

Table III. The frequency of non-dippers and dippers in sodium sensitive hypertensive patients on low-and high-sodium diet

\begin{tabular}{|c|c|c|c|}
\hline & Non-dippers & Dippers & $P$ value \\
\hline Low-sodium diet & $\begin{array}{c}15 \\
(21.7 \%)\end{array}$ & $\begin{array}{c}54 \\
(78.3 \%)\end{array}$ & \multirow{2}{*}{$\begin{array}{l}p<0.001 \\
\chi^{2}=16.73\end{array}$} \\
\hline High-sodium diet & $\begin{array}{c}45 \\
(65.0 \%)\end{array}$ & $\begin{array}{c}24 \\
(35.0 \%)\end{array}$ & \\
\hline
\end{tabular}

Table IV. The mean value ( \pm SD) of creatinine clearance (Ccr), urinary sodium (UNa), potassium (UK), urinary volume (Uvol), concentrations of plasma renin activity (PRA) and aldosterone in sodium sensitive hypertensive patients on low-and high-sodium diet

\begin{tabular}{|l|c|c|c|}
\hline & Low sodium diet & $\begin{array}{c}\text { High sodium } \\
\text { diet }\end{array}$ & P value \\
\hline Ccr [ml/min] & $103.5 \pm 7.3$ & $116.8 \pm 12.6$ & $\mathrm{p}<0.001$ \\
\hline $\begin{array}{l}\text { UNa } \\
{[\mathrm{mmol} / 24 \mathrm{~h}]}\end{array}$ & $21.8 \pm 6.3$ & $241.5 \pm 6.4$ & $\mathrm{p}<0.001$ \\
\hline $\begin{array}{l}\text { UK } \\
{[\mathrm{mmol} / 24 \mathrm{~h}]}\end{array}$ & $49.9 \pm 3.4$ & $50.1 \pm 4.2$ & $\mathrm{~ns}$ \\
\hline $\begin{array}{l}\text { Uvol } \\
{[\mathrm{ml} / 24 \mathrm{~h}]}\end{array}$ & $1183 \pm 137$ & $1222 \pm 136$ & $\mathrm{~ns}$ \\
\hline $\begin{array}{l}\text { PRA } \\
{[\mathrm{ng} / \mathrm{Al} / \mathrm{ml} / \mathrm{h}]}\end{array}$ & $4.82 \pm 0.35$ & $1.20 \pm 0.38$ & $\mathrm{p}<0.05$ \\
\hline $\begin{array}{l}\text { Aldosterone } \\
\text { [pg/ml] }\end{array}$ & $396.0 \pm 28.3$ & $127.1 \pm 24.5$ & $\mathrm{p}<0.001$ \\
\hline
\end{tabular}

\section{Discussion}

Basic advantages offered by $24 \mathrm{~h}$ ABPM include the possibility to assess circadian blood pressure profiles, daytime and nocturnal blood pressure and its diurnal variations as well as the magnitude of nocturnal fall which allows to identify the dipper and non-dipper patterns [20, 24-27]. Moreover, it has been well documented that blood pressure values in ABPM better correlate with left ventricle mass, severity of kidney damage, prevalence of cardiovascular events and changes in eye fundoscopy than blood pressure values measured by traditional methods [28-31]. It also has been suggested that ABPM has better sensitivity in the prediction of the rate of hypertension complications and cardiovascular death, and overall prognosis $[32,33]$.

Our results suggest that diminished salt-induced nocturnal blood pressure fall could be a characteristic feature of salt-sensitive hypertension. Interestingly, many of dippers on a low sodium diet developed not desired non-dipping blood pressure pattern on a high sodium diet. This finding confirms a similar conclusion reported in Japan population [21], although in humans the blood pressure performance in response to high salt load can be modulated by dietary potassium intake [34]. The essential influence of dietary sodium on blood pressure profiles was demonstrated in experimental studies. In spontaneously hypertensive rats (SHR), a high sodium diet deteriorated normal circadian profile of blood pressure [35] suggesting the maintenance of stable dietary sodium as a crucial factor in assessments of variability and circadian rhythm of blood pressure; however, data regarding this issue are still scarce and hence, the mechanism of high blood pressure variability and diminished nocturnal fall in salt-sensitive patients receiving high sodium diet remains unclear [21,34]. It should be noted that increasing evidence suggests that high sodium diet may alter several pathways regulating blood pressure, namely the sympathetic activity $[2,15]$, volemia [2], renin-angiotensin-aldosterone system activity [36], insulin release and insulin sensitivity [36, 37], intracellular sodium and calcium concentration $[36,37]$, 
kidney hemodynamics, and endogenous nitric oxide synthesis [38]. As all these pathways are greatly involved in the modulation of circadian blood pressure profile and variation, it can be speculated that they may play a role in the diminution of nocturnal fall and increased variability of blood pressure observed in our study. Previous studies demonstrated that the activity of the autonomic nervous system, especially the sympathetic activity, influences the range of nocturnal fall $[39,40]$. It has been suggested that in salt-sensitive subjects the retention of sodium and blood pressure increase are associated with increased sympathetic activity [41-44], resulting in a shift of the pressure-natriuresis mechanism [44] and increase of arterial reactivity to vasopressor compounds [42]. In healthy individuals, nocturnal fall is a result of dominating parasympathetic activity during sleep [45]. In this context, it can be assumed that in some hypertensive patients a shift from dominating parasympathetic activity during nighttime to increased sympathetic activity may lead to nocturnal hypertension and change in circadian blood pressure profile.

Non-dipping hypertension was found in conditions associated with hypervolemia such as primary hyperaldosteronism or chronic kidney disease [46]. Both clinical and experimental studies demonstrated that salt sensitivity is associated with hypervolemia and diminished natriuretic and diuretic responses to sodium load; therefore, it can be suspected that in sodium-sensitive patients, high sodium intake may deteriorate the blood pressure circadian rhythm. In salt-sensitive patients, the attenuated blood pressure nocturnal fall in response to high sodium diet may be explained, at least partially, by changes in the renin-angiotensin-aldosterone system. Brandenburger et al. [47] demonstrated that a decrease in renin release during the night was responsible for the magnitude of blood pressure nocturnal fall. They showed that inhibition of the renin-angiotensin-aldosterone system in response to sodium load resulted in the significant reduction of circadian differences in the day-and nighttime blood pressure. Similarly, our study demonstrated lower plasma renin activity on a high sodium diet in comparison with low sodium diet suggesting that ineffective inhibition of the renin-angiotensin-aldosterone system in salt-sensitive patients may contribute to the diminished nocturnal blood pressure fall. On each of the diet 24-h ABPM was performed.

\section{Conclusions}

1. Aside of significant blood pressure rise, in patients with hypertension a high sodium diet induced the diminution of nocturnal fall.
2. Our results suggest that in salt-sensitive patients the reduction of salt intake may decrease blood pressure and restore its circadian profile and thus lead to the reduction in the rate of complications of hypertension.

\section{References}

1. Sullivan J.M., Ratts T.E., Taylor J.C. Hemodynamic effects of dietary sodium in man: a preliminary rapport. Hypertension 1980; 2: 506-514.

2. Weinberger M.H., Miller J.Z., Luft F.C., Grim C.E., Fineberg N.S. Definitions and characteristics of sodium sensitivity and blood pressure resistance. Hypertension 1986; 8 (Suppl. II): II127-134.

3. Sullivan J.M., Ratts T.E. Sodium sensitivity in human subjects: Hemodynamic and hormonal correlates. Hypertension 1988; 11 : 717-723.

4. Sullivan J.M. Salt sensitivity: Definition, conception, methodology, and long-term issues. Hypertension 1991; 17 (Suppl. I): I61-68.

5. Luft F.C., Miller J.Z., Grim C.E. et al. Salt-sensitivity and resistance of blood pressure: age and race as factors in physiological responses. Hypertension 1991; 17 (Suppl. 1): I102-108.

6. Tuck M.L. Role of salt in the control of blood pressure in obesity and diabetes mellitus. Hypertension 1991; 17 (Suppl.): I135-142.

7. Weidmann P., Ferrari P. Central role of sodium in hypertension in diabetic subjects. Diabetes Care 1991; 14: 220-232.

8. Dyer A.R., Stamler R., Elliott P., Stamler J. Dietary salt and blood pressure. Nat. Med. 1995; 1: 994-996.

9. Harmsen E., Leenen F.H. Dietary sodium induced cardiac hypertrophy. Can. J. Physiol. Pharmacol. 1992; 70: 580-586.

10. Heimann J.C., Drumond S., Alves A.T., Barbato A.J., Dichtchekenian V., Marcondes M. Left ventricular hypertrophy is more marked in salt-sensitive than in salt-resistant hypertensive patients. J. Cardiovasc. Pharmacol. 1991; 17 (Suppl. 2): S122-124.

11. Julius S. Corcoran Lecture: Sympathetic hyperactivity and coronary risk in hypertension. Hypertension 1993; 21: 886-893.

12. Lind L., Lithell H., Gustafsson I.B., Pollare T., Ljunghall S. Metabolic cardiovascular risk factors and sodium sensitivity in hypertensive subjects. Am. J. Hypertens. 1992; 5: 502-505.

13. Uzu T., Kazembe F.S., Ishikawa K., Nakamura S., Inenaga T., Kimura G. High sodium sensitivity implicates nocturnal hypertension in essential hypertension. Hypertension 1996; 28: 139-142.

14. The Seventh Report of the Joint National Committee on Prevention, Detection, Evaluation and Treatment of High Blood Pressure. The JNC 7 Report. JAMA 2003, 289: 2560-2575.

15. World Health Organisation: Arterial hypertension: Report of WHO expert committee. WHO Tech. Res. Ser. 1978; 628: 1.

16. Tykarski A., Narkiewicz K., Gaciong Z. et al. Guidelines for the management of hypertension. Arterial Hypertens. 2015; 19: 53-83.

17. Grim C.E., Weinberger M.H., Higgins J.T., Kramer N.J. Diagnosis of secondary forms of hypertension. A comprehensive protocol. JAMA 1977; 237: 1331-1335.

18. Tykarski A., Narkiewicz K., Gaciong Z. et al. 2015 Guidelines for management of hypertension (Part 9). Arterial Hypertens. 2015; 19: 101-109.

19. Bigazzi R., Bianchi S., Baldari D., Sgherri G., Baldari G., Campese V.M. Microalbuminuria in salt-sensitive patients. A marker for renal and cardiovascular risk factors. Hypertension 1994; 23: 195-199.

20. Grupa robocza Polskiego Towarzystwa Nadciśnienia Tętniczego: 24-godzinne automatyczne monitorowanie ciśnienia tętniczego krwi w diagnostyce i terapii nadciśnienia tętniczego — stan obecny i perspektywy. Pol. Arch. Med. Wewn. 1993; 89: 251-254.

21. Higashi Y., Oshima T., Ozono R. et al. Nocturnal decline in blood pressure is attenuated by $\mathrm{NaCl}$ loading in salt-sensitive patients with essential hypertension. Hypertension 1997; 30: 163-167.

22. Staessen J., Fagard R., Lijnen P., Thijs L., van Hoof R., Amery A. Reference values for ambulatory blood pressure: a meta-analysis. J. Hypertens. 1990; 8 (Suppl. 6): S57-64. 
23. Januszewicz W., Sznajderman M., Szczepańska-Sadowska E. Nadciśnienie tętnicze. PZWL, Warszawa 1993.

24. Bianchi S., Bigazzi R., Baldari G., Sgherri G., Campese V.M. Diurnal variations of blood pressure and microalbuminuria in essential hypertension. Am. J. Hypertens. 1994; 7: 23-29.

25. Pickering T. Short-term variability of blood pressure, and the effects of physical and mental activity. Ambulatory monitoring and blood pressure variability. Science Press 1995; 4: 1-5.

26. Pickering T. Variability of blood pressure. Blood Press. Monit. 1998; 3: $141-145$.

27. Redon J., Liao Y., Lozano J.V., Miralles A., Pascual J.M., Cooper R.S. Ambulatory blood pressure and microalbuminuria in essential hypertension: role of circadian variability. J. Hypertens. 1994; 12: 947-953.

28. Mochizuki Y., Okutani M., Donfeng Y. et al. Limited reproducibility of circadian variation in blood pressure dippers and nondippers. Am. J. Hypertens. 1998; 11: 403-409.

29. Parati G., Pomidossi G., Albini F., Malaspina D., Mancia G. Relationship of 24-hour blood pressure mean and variability to severity of target organ damage in hypertension. J. Hypertens. 1987; 5: 93-98.

30. Perloff D., Sokolow M., Cowan R. The prognostic value of ambulatory blood pressure monitoring in treated hypertensive patients. J. Hypertens. 1991; 9 (Suppl. 1): S33-40.

31. Verdecchia P., Borgioni C., Ciucci A. et al. Prognostic significance of blood pressure variability in essential hypertension. Blood Press. Monit. 1996; 1: 3-11.

32. Redon J., Campos C., Narciso M.L., Rodicio J.L., Pascual J.M., Ruilope L.M. Prognostic value of ambulatory blood pressure monitoring in refractory hypertension. A prospective study. Hypertension 1998; 31: 712-718.

33. Zanchetti A. The role of ambulatory blood pressure monitoring in clinical practice. Am. J. Hypertens. 1997; 10: 1069-1080.

34. Wilson D.K., Sica D.A., Miller S.B. Effects of potassium on blood pressure in salt-sensitive and salt-resistant black adolescents. Hypertension 1999; 34: 181-186.

35. Calhoun D.A., Zhu S., Wyss J.M., Oparil S. Diurnal blood pressure variation and dietary salt in spontaneously hypertensive rats. Hypertension 1994; 24: 1-7.
36. Oshima T., Matsuura H., Matsumoto K., Kido K., Kajiyama G. Role of cellular calcium in salt sensitivity of patients with essential hypertension. Hypertension 1988; 11: 703-707.

37. Verdecchia P., Schillaci G., Boldrini F., Zampi I., Porcellati C. Variability between current definitions of "normal" ambulatory blood pressure: implications in the assessment of white coat hypertension. Hypertension 1992; 20: 555-562.

38. Higashi Y., Oshima T., Watanabe M., Matsuura H., Kajiyama G. Renal response to $\mathrm{L}$-arginine in salt-sensitive patients with essential hypertension. Hypertension 1996; 27: 643-648.

39. , Imai Y., Abe K., Munakata M. et al. Cicardian blood pressure variations under different pathophysiological conditions. J. Hypertens. 1990; 8 (Suppl. 7): S125-132.

40. Littler W.A., Watson R.D., Stallard T.J. Cicardian variation of blood pressure. Lancet 1978; 1: 995-996.

41. Campese V.M., Romoff M.S., Levitan D., Saglikes Y., Friedler R.M., Massry S.G. Abnormal relationship between $\mathrm{Na}+$ intake and sympathetic nervous system activity in salt-sensitive patients with essential hypertension. Kidney Int. 1982; 21: 371-378.

42. Gill J.R., Güllner G., Lake C.R., Lakatua D.J., Lan G. Plasma and urinary catecholamines in salt-sensitive idiopathic hypertension. Hypertension 1988; 11: 312-319.

43. de la Sierra A., Lluch M.M., Coca A. et al. Fluid, ionic and hormonal changes induced by high salt intake in salt-sensitive and salt-resistant hypertensive patients. Clin. Sci. (Colch.) 1996; 91: 155-161.

44. Elser M., Jennings G., Korner P. et al. Assessment of human sympathetic nervous system activity from measurements of norepinephrine turnover. Hypertension 1988; 11: 3-20.

45. Furlan R., Guzzetti S., Crivellaro W. et al. Continous 24-hour assessment of the neural regulation of systemic arterial pressure and RR variabilities in ambulant subjects. Circulation 1990; 81: 537-547.

46. Tanaka T., Natsume T., Shibata H. et al. Cicardian rhythm of blood pressure in primary aldosteronism and renovascular hypertension analysis by consignor method. Jpn. Circ. J. 1983: 47: 788-794.

47. Brandenbereger G., Follenius M., Simon C., Ehrhart J., Libert J.P. Nocturnal oscillations in plasma renin activity and REM-NREM sleep cycles in humans: a common regulatory mechanism? Sleep 1989; 11: 242-250. 